\title{
Exploring Parents' Views Concerning Emergency Remote Teaching
}

\author{
Evangelia Filippakopoulou, Sarah Vlachou, Eleni Malliou, and Spyridon Doukakis
}

\begin{abstract}
During the Covid-19 pandemic, educational institutions worldwide continued to operate through online education. The present study investigates the way in which parents from a prefecture of western Greece that includes urban, semi-urban and rural population, faced the new form of educational process. Through a questionnaire and group interviews, parents shared their views concerning online education and emergency remote teaching. The participants are parents to children who attend primary and lower secondary education. The parents stated that their children faced had difficulties during distance education. Moreover, they felt the need to intervene in order to help their children in this new way of education. More specifically, the parents of the present study point out that 1) in order for emergency remote teaching to be able to offer learning, a comprehensive training of teachers and proper planning of schools is necessary, 2) it is necessary to limit the offered courses in the online program and 3) education in physical environments is of great value and is irreplaceable.
\end{abstract}

keywords - emergency remote teaching, parents, primary students, secondary students.

\section{INTRODUCTION}

During the COVID-19 pandemic, in many countries, primary and secondary schools operated either though physical presence when permitted by health conditions or online. The above model was particularly demanding for students, teachers and parents and constituted a difficult new structure for the educational community.

Online education, due to its immediate implementation, was not an organized distance learning structure, but was an emergency remote teaching structure, as the existing school buildings could not be used for lessons with the physical presence of teachers and students. School units and teaching staff were asked to respond to this new reality without having the necessary scientific knowledge to implement distance education, not even empirical knowledge as it did not belong to its practices.

In all primary and secondary schools, classes continued to be conducted through digital platforms such as WebEx, Microsoft Teams, Zoom and others, so that synchronous education took place. In addition, the available repositories of digital educational material were utilized, as well as course management systems, such as Moodle, where teachers provided additional material to their students. Moreover, course management systems were used by the teachers to post the assignments and for the students to deliver the assignments. Some teachers used email or communication software such as Viber to distribute the assignments to the students' parents. The e-lessons were held at set times and preferably at the same time as the school schedule. According to the literature, difficulty in managing this new situation was observed, recorded, and attributed to the lack of technological equipment and the lack of training [1].

This emergency situation and the way it evolved was the trigger for this study. In the next section, a brief bibliographic review of existing studies is attempted and then the research and its findings are presented. The study is completed by highlighting specific conclusions in relation to the research questions and suggestions for the benefit of the family environment.

\section{LITERATURE REVIEW}

In 2019, the appearance of the Covid-19 pandemic resulted in the drastic change of people's everyday life. Daily life was moved to the screen and to the internet world. This also happened in the field of education, where students and teachers continued their education cooperation from home.

Several studies worldwide analyzed this new reality by investigating parents' views on online education. In recent research, parents whose children attended kindergarten declared negative towards their children's distance education with the use of digital technologies. More specifically, they highlighted that because of their children's age and educational needs (socialization, contact with peers, activities) education through the digital device's screen is incomplete and restrictive. At the same time, they argued that teachers were not scientifically trained in these teaching approaches and themselves as parents did not have the necessary support from the state and knowledge required [2].

A recent survey revealed that although some mothers have difficulty in supporting their children in remote education, openness to new situations and the receptivity that themselves demonstrate help their children adapt faster to the new framework [3]. Research considers significant and highlights that a successful approach of emergency teaching is to create and adopt a daily fixed program for children, making the new process more manageable [4].

In the Eastern countries, parents declare negative in the distance learning process, claiming that it does not offer their 
children the expected learning outcomes due to the deficient training of teachers and their lack of their own training so that they can respond to the needs that are presented [5]. At the same time, in the US, research shows that mothers usually take up a) the control of the child's presence in remote education and b) child support when he/she can't fully respond to the new teaching mode. However, it seems that, because the parents had to work from their home also, online education resulted in conflicts and sometimes to an unstable environment for the child [6].

In Europe, studies have shown that children, teachers, and parents living in countries that the people are more familiar with the use of technology did not deal with adjustment problems. From the research it seems that parents did not have problems associated with potential deficiencies of teachers or with difficulties in managing their children's daily work. In addition, it is interesting that some parents stated that their children also had the opportunity to improve technologically due to the use of the Internet and the various software programs [7].

From the above, it seems that parents' views on online education offer interesting findings that can contribute to improving online education and enhance learning. Taking advantage of the above findings, in the next section, the research framework is presented.

\section{RESEARCH FRAMEWORK}

\section{A. Research}

This study was carried out during the period of distance education in a prefecture of Western Greece that includes urban, semi-urban, and rural population. The survey attempted to record parents' views: (a) for the online teaching of their children; (b) the effectiveness of the teaching mechanism (Ministry of education, school units, digital technologies), (c) the teachers and (d) for whether there were potential benefits for students through this process.

The naturalistic-interpretive example was selected in order to attempt to understand how parents interpret the world in which they are located. The research approach was qualitative and the research tools that were used are the questionnaire and the focus groups.

\section{B. Design and Sample}

Twelve (12) adult parents were selected to conduct the qualitative research. Restrictions on physical meetings due to COVID-19 and at the same time the need to protect people's safety have not facilitated physical presence meetings, resulting in all meetings taking place online. Ten women and two men participated in the survey. Ten of the participants were working remotely and from their home, hence present during their children's internet courses. When selecting the participants, (a) their gender; (b) their profession; (c) their educational background and d) their social background had not been taken into account.

Only parents of primary and lower secondary school students were selected, as in these age groups students are less autonomous than upper secondary school students. The study involved 7 parents of lower secondary school students and 5 parents of primary school students. The data of the participants are presented in Table I.

\begin{tabular}{ccccc}
\multicolumn{5}{c}{ TABLE I: CHARACTERISTICS } \\
\hline \hline No & $\begin{array}{c}\text { Parent } \\
\text { Gender }\end{array}$ & Age & Child School & $\begin{array}{c}\text { Parents } \\
\text { educational } \\
\text { background }\end{array}$ \\
\hline 1 & Mother & $41-50$ & Lower Secondary School & $\begin{array}{c}\text { BSc Degree } \\
\text { Secondary }\end{array}$ \\
2 & Father & $41-50$ & Primary School & $\begin{array}{c}\text { Education } \\
\text { MSc Degree }\end{array}$ \\
3 & Mother & $41-50$ & Lower Secondary School & Secondary \\
4 & Mother & $31-40$ & Primary School & Education \\
5 & Mother & $41-50$ & Primary School & MSc Degree \\
6 & Mother & $41-50$ & Lower Secondary School & BSc Degree \\
7 & Mother & $41-50$ & Primary School & BSc Degree \\
8 & Mother & $41-50$ & Primary School & PhD \\
9 & Father & $>51$ & Lower Secondary School & BSc Degree \\
10 & Mother & $31-40$ & Lower Secondary School & MSc Degree \\
11 & Mother & $41-50$ & Lower Secondary School & BSc Degree \\
12 & Mother & $41-50$ & Lower Secondary School & MSc Degree \\
\hline \hline
\end{tabular}

\section{Data Collection}

The collection of the research data was accomplished by using two tools. In particular, the questionnaire and focus groups were used as research tools. The use of two different methodological tools aimed to increase the reliability and correctness of responses due to the small number of sample and the time constraint to carry out the survey. At the same time, however, the two tools offered parents the opportunity to redefine their views through the focus groups. The software programs used to implement the data collection were, respectively, Google Forms and Skype.

\section{Questionnaire}

The questionnaire was the first data collection tool. The questionnaire was sent to the participants via email. It included twenty-six (26) questions divided into three (3) parts. The first part included the demographics of the children of the participating parents, the second part consisted of closed-type and multi-choice questions relatively a) with the potential control of the child by the parent in the context of online education and b) the child's presence on the remote teaching education. Finally, the third part included openended questions where parents were given the opportunity to express their views on online teaching.

\section{E. Focus Groups}

Participants were equally divided into two (2) groups and were free to discuss freely around the issue of their children's online teaching. In addition, they had the freedom to further develop their views on the questionnaire's questions. The participants were asked to answer honestly to all questions. Catering groups were created on the basis of the time that facilitated participants. Each group had ninety (90) minutes at their disposal.

For the two stages of the process, participants were informed in advance about the process, safety, and anonymization of their data.

Analysis of quality data collected, took place using the NVivo software. 


\section{FINDINGS}

One of the first issues the research focused on was how much time a parent spends with their child during online lessons. According to the answers, the parents were divided into three categories. Three (3) parents, with children in lower secondary education, reported that they sit in with their children throughout the course, five (5) parents, with children in primary education, stated that they sit with them only a little while at the beginning and four (4) parents, of which only one (1) child is in primary school, state that they do not need to be with their children because they are autonomous.

Then, the issue of monitoring and controlling the consistency of the child, in terms of his obligations, in the context of online courses was raised. According to the answers, eight (8) parents stated that they control their children, stating characteristics:

"We talk daily about the lessons and focus on the problems s/he may have encountered and her/his questions. We are also preparing together for quizzes and tests."

"Almost like at school. Whatever tasks he has to do, he notes them and does them. We check them together and I send them to the teacher via Viber. "

Parents were then asked to determine if there were any benefits to e-learning in relation to physical education. All twelve parents stated that their children did not benefit from the new way of teaching. The following answers were interesting:

"Not at all. The immediacy of the class is not comparable."

"No. In the physical order there is constant visual and auditory communication, participation, interaction. None of this exists in online education. "

"I believe for many reasons that it cannot benefit in relation to physical education, as: 1) when it comes to adolescents, the physical presence in the classroom and communication with their classmates at breaks or at least on the way to and from school is very important, 2) in some lessons especially in music lessons (e.g. choir, ensembles, concerts) or physical exercise (e.g. gymnastics) online education becomes boring for children, it does not excite them and ultimately does not fulfill the purpose of the lesson, 3) there is no live interaction between teacher and student, 4) noble rivalry between children is not enhanced."

However, when the parents were subsequently asked whether their children benefited from the online education, six (6) parents replied that the children did not particularly benefit from this process, while the rest stated that they did not benefit at all. In other words, it seems that even the lack of online education for parents offers some benefits in relation to the lack of education.

The change in parents' approach becomes even more apparent when asked if their child learned through online teaching. Ten parents stated that their children learn moderately through distance teaching, while two stated that learning is not achieved. In particular, they pointed out, that they were surprised by the fact that the system had functioned better within the lower secondary education compared to the primary education.
"It was not good in primary school. A very good job was done in lower secondary schools. Gymnastics with quizzes, body move, gymnastics in terms of knowledge."
"He certainly learns but gaps are also created. Especially in practical courses e.g., mathematics"
"He learns, but not the same as the classroom with physical presence. Fortunately, he is a smart and responsible child, so he knows that it is for his own benefit to be careful. In the online lesson, the individual responsibility of each student plays a bigger role because it is much easier to "stay away" from the lesson. Excuses like "I can't connect or the microphone broke" etc. they are innumerable."
"I believe he has the opportunity to learn. The difference arises due to the difficulties and the vary problems. And I consider the socialization of the child in the physical school environment to be basic, something that the online method does not offer. "

Commenting on the adequacy of the Ministry of Education in meeting the technological needs and in informing and preparing parents for distance learning, the participating parents pointed out that there were technological and managerial shortcomings in the design.

"Of course, due to financial hardship."

"Of course. On an income basis, families had to be given both technical equipment and free internet access so that no child or teacher was left out of the education process. After all, let us not forget that we came out of a period of deep economic crisis and many households due to the coronavirus and the measures taken were in a difficult situation without being able to provide even the necessities.

"Only if all children have access to the educational process, we have the right to talk about free public education."

"A large percentage of teachers and parents do not know how to handle and face difficulties. Students at a lower rate."

"There were instructions from the State, I think it might have been better if some relevant seminars had been given to parents and students, because in the beginning the children had problems (e.g., for the initial connections on the platforms of the Ministry) and parents did not know how to help them. With a joint effort, of course, we finally succeeded. I think that the teachers made some relevant effort through seminars from the Ministry."

Finally, when asked if online education could be part of school planning, six parents said no, while the other six said it could be used by the education system as an alternative way of teaching or outweighing educational deficiencies. 
"Of course not. I do not recognize this as school. It is a solution of necessity."

"No. If this is done, the pandemic will not have been fought. The main goal is to fight it so that new things are not established as permanent and abnormal. "

"Yes, I believe that in the era we have entered, the internet should be a continuation of the school environment so that both students and teachers and parents interact by exchanging views, learning and helping the educational process."

"In case of absence of a child, he could be informed by the platform about the lesson delivered and the tasks he has."

After completing the questionnaire process, the focus groups followed. As already mentioned, the participants were divided equally into two groups and were free to discuss anything that concerned them about the issue of their children's online education. In addition, they had the freedom to further develop their views on the questionnaire questions. The members of the first group re-evaluated their answers and without deviating from them tried to explain them. In the attempt to discuss new issues, the group did not respond and remained steadfast in the answers it had given. More specifically, the members of the first focus group agreed that: a) their children did not benefit from this way of teaching, b) the teachers did not do the same job as they offered at school, c) there is a lack of infrastructure and training and d) the children must return to school as soon as possible. The thoughts shared by some of the parents are typical.

"The learning was excellent. The lesson was not bad. But the lesson with physical presence is irreplaceable"

"There was refusal by older teachers because they did not have the knowledge or technology at home. It was necessary to show understanding to the younger ones."

"We can learn from this and see what we can change. I am positive in the development. But direct contact is key. Many children did not have machines or connections. "

"School is a cornerstone and should not be replaced. It helps the sociability of children."

The second group had an interactive discussion and an exchange of views. They did not cling to the answers already given in the questionnaire and viewed the group interview as a new opportunity to express their views. The participants: a) expressed their concern about the lack of teacher training, b) supported the view that it is the personal responsibility of each teacher to adapt to the new way of teaching and be just as effective, c) identified the ineffectiveness of online teaching due to the lack of modernization of educational institutions and the way they operate and e) argued that distance learning can be continued to help children who for health reasons cannot attend physical school and their lessons or due to bad weather conditions. Typical are the answers given by specific parents to the focus group.
"Teachers have not learned to handle tools. Children ask why they do not express their opinions on the subject of online education. How can they do that? The mathematician turns her computer on the camera so they can see what she is writing."

"Computer use is a burdensome condition. We did not know it and did not know its function concerning teaching."

"School is useful and necessary. It is the first society that children enter. They leave the security of the family and are faced with managing situations on their own and proving what they are."

"An alternative way of teaching for children with learning difficulties. Technological language to be a general education course. "

From the qualitative data analysis performed with NVivo, the words that dominated the parents' speech were children, physical, presence, speech, learning, online (Fig. 1).

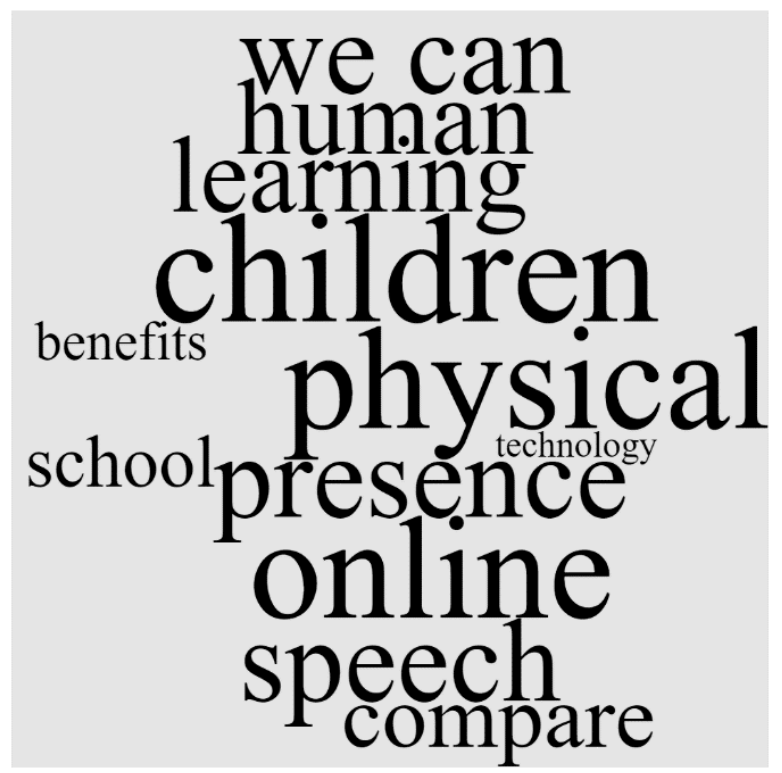

Fig. 1. Word cloud.

Their priority is their children, and they believe it is important for their children to be able to contact with their peers and teachers.

Ten out of twelve parents identified that their children do learn - given that they lacked access to school buildings- in this new way of teaching that prevailed and was established during Covid-19. In addition, they stated that their child is given the opportunity to do his homework in creative and new ways of learning.

Their remarks on the lack of educational material based on the new way of teaching and on the difficulty of teachers in managing digital technologies were also evident (Fig. 2).

Regarding the desire of parents to make online education a basic way of educating their children and to include it in the school curriculum, the word lesson is the connecting link in their answers (Fig. 3). 


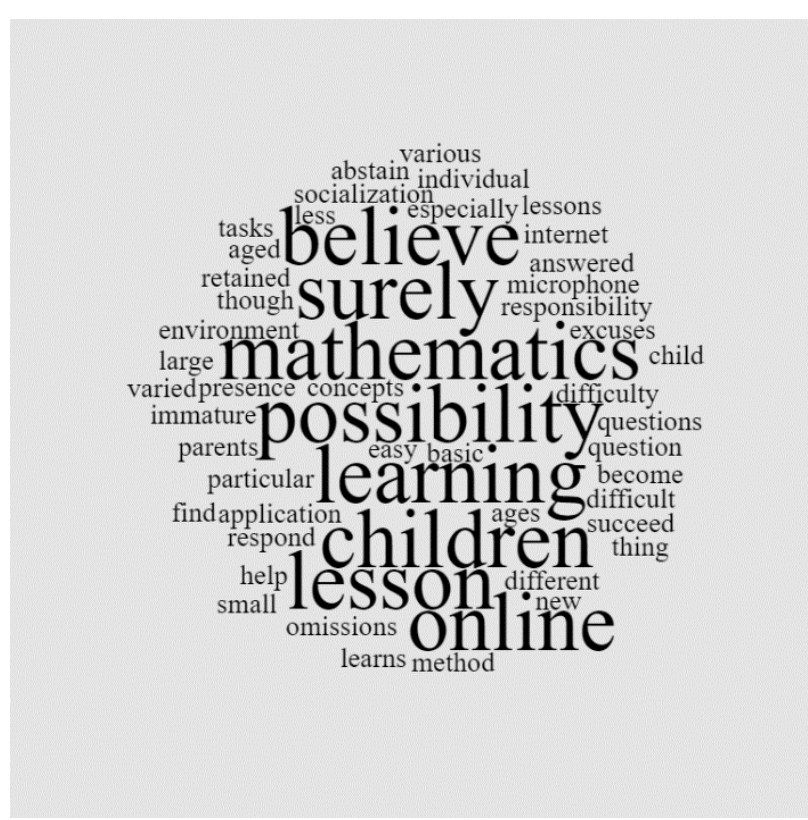

Fig. 2. Word cloud.

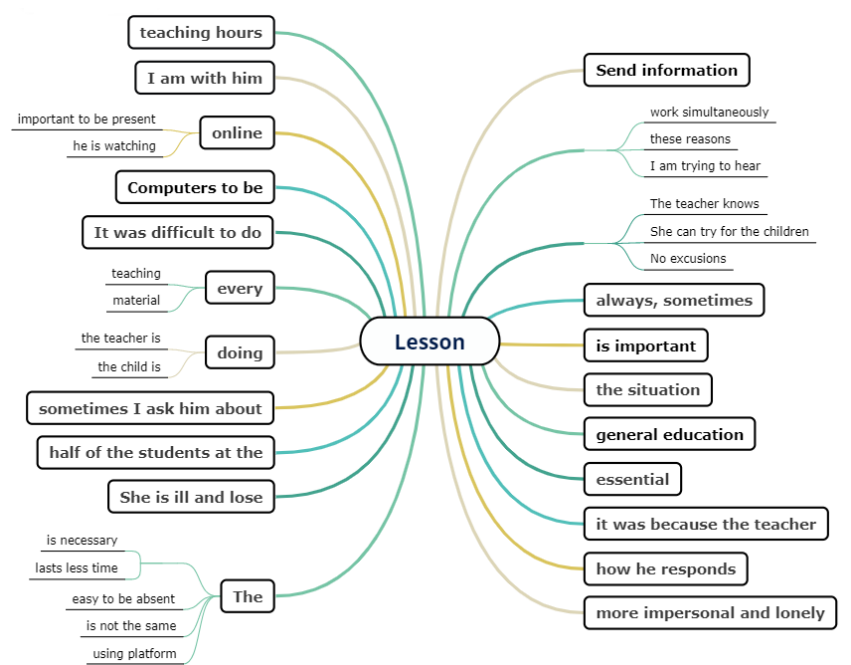

Fig. 3. Lesson.

Overall, the answers given in relation to the two methodological tools, which were analyzed through NVivo, are shown in Fig. 4 (the first six columns).

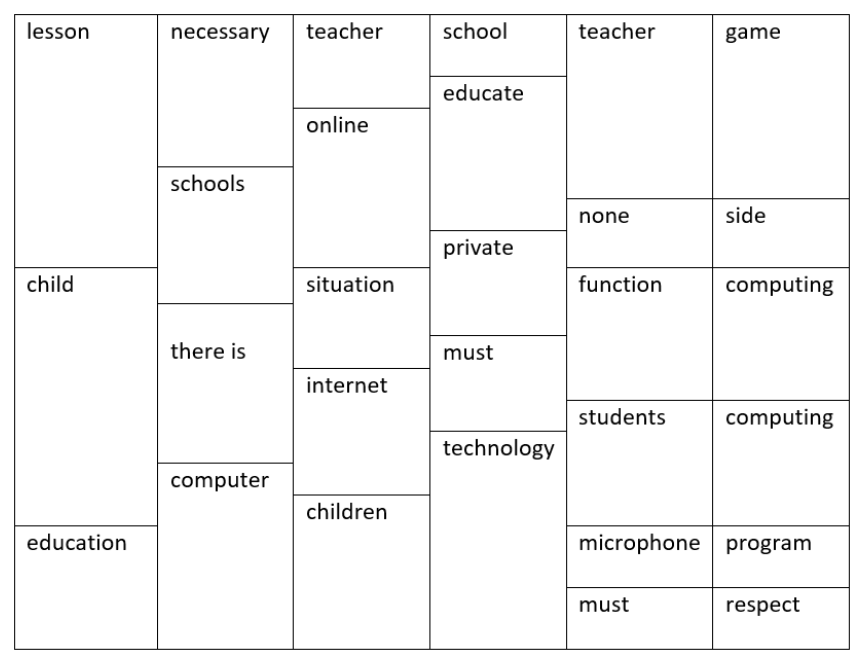

Fig. 4. Important words.

\section{CONCLUSION}

Analyzing the data obtained from the research on online education during the Covid-19 period, it was found that some parents had better control over their child's school routine. It is also interesting that the parents of the children in the lower secondary schools declare a more regular presence compared to the parents of the children in the primary schools. The presence of the parent during the lessons proved to be useful both for the child and for the parents in order to obtain a complete picture of their child's education.

Parents state that children do not benefit from distance education and that this alternative way of teaching cannot replace education in the schools mainly due to the lack of personal contact with teachers and classmates. At the same time, they express their moderate satisfaction with their children's school performance.

The participating parents believe that the Ministry of Education should somehow cover the technological shortages of children and teachers. At the same time, they stated that the Ministry of Education needs to invest in improving the technological knowledge of teachers.

The established vision and the tradition in the way children are educated confirms the difficulties but also the refusal of some parents for change. Through the dialogue it was seen that distance education could become a means of enhancing the school life of children.

Human education is the basis on which the evolution of the human race is based. For this reason, even emergency remote teaching was necessary for children, parents, and society. The role played by teachers was particularly important and at the same time demanding. In this way they managed to contribute to the education of the children so that they would not stay away from educational activities for a long time.

\section{APPENDIX}

The 26 questions included in the questionnaire are the following:

- Student Demographics:

- How many children do you have who attend primary or lower secondary school?

- Are you the mother or father of the children?

- Regardless of the number of children you have, choose the class that one of them goes to.

- What is the gender of this child?

- Introduce a typical day of your child's online learning.

- Parent-Child Presence \& Control:

- For how long are you with your child while attending online class?

- Due to the global pandemic, do you feel more aware of the way your child's is taught in school? Explain why.

- Do you check your child's attendance at online classes?

- How do you check your child's attendance at online classes?

- Do you check your child's consistency towards his / her obligations during the online lessons?

- How do you check if your child is consistent with 
their responsibilities in online lessons?

- Online Education \& Parents:

- How easy is it to communicate with your child's teachers?

- Do you have the opportunity to discuss your child's progress and ask for help from teachers for any difficulties? Explain why.

- Do you think your child benefits from online education?

- Do you think that the child benefits from online education more than physical education? Explain why.

- Do you think that your child learns through online education? Explain why.

- Do you think that the Ministry of Education should have provided households and teachers with appropriate technological equipment for online education? Explain why.

- Do you think that the Ministry of Education should have to prepared parents, students, and teachers so that they can easily manage issues related to online education? Explain why.

- If you had the responsibility to manage the issue of online school education, how would you manage the system so that you could get the best possible performance from both teachers and students? Justify your answer.

- What would you change and maintain in terms of online education structures after the pandemic? Explain why.

- Would you like online education to be part of the educational process after the pandemic? If so, describe how.

- Do you think that online education affects the parents in terms of their children's education? Are any existing disagreements becoming more intense and intrusive? Explain why?

- Do you think that the change in the financial situation of the family (closing businesses, dismissals, etc.) affects the balance of the couple, so that the psychology of the children is affected and therefore their performance? Explain why.

- Select the age group you belong to.

- What is your level of study?

- What is your profession?

\section{REFERENCES}

[1] Nikiforos S., Tzanavaris S., \& Kermanidis K. L. Post-pandemic Pedagogy: Distance Education in Greece During COVID-19 Pandemic Through the Eyes of the Teachers. European Journal of Engineering and Technology Research, 2020.

https://www.ejers.org/index.php/ejers/article/view/2305

[2] Lau E. Y. H. \& Lee K. Parents' views on young children's distance learning and screen time during COVID-19 class suspension in Hong Kong. Early Education and Development, 2021;32(6):863-880. DOI:10.1080/10409289.2020.1843925.

[3] Misirli O., Ergulec F. Emergency remote teaching during the COVID19 pandemic: Parents experiences and perspectives. Educ Inf Technol, 2021. DOI: 10.1007/s10639-021-10520-4.

[4] Cahapay M. B. Involvement of Parents in Remote Learning of Children amid COVID-19 Crisis in the Philippines: A Transcendental Phenomenology. International Journal of Sociology of Education, 2021;10(2):171-192. DOI: 10.17583/rise.2021.7317.
[5] Dong C., Cao S., \& Li H. Young children's online learning during COVID-19 pandemic: Chinese parents' beliefs and attitudes. Children and Youth Services Review, 2020;118:105440.

[6] Calarco J. M., Meanwell E., Anderson E., \& Knopf A. My husband thinks I'm crazy: COVID-19-related conflict in couples with young children. SocArXiv, 2020. DOI: 10.31235/osf .io/cpkj6.

[7] Trültzsch-Wijnen C., \& Trültzsch-Wijnen S. Remote schooling during the Covid-19 lockdown in Austria, 2020. DOI: 10.25598/KiDiCoTiAT-2020-1S

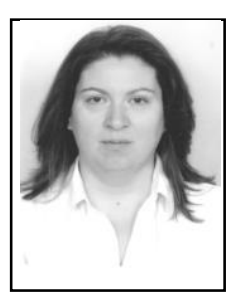

Evangelia Filippakopoulou graduated from the Computer Science and Information Technology Department of Western Macedonia, Kastoria (2010) and completed her master's degree in the Department of Informatics, Ionian University, Corfu (2021).

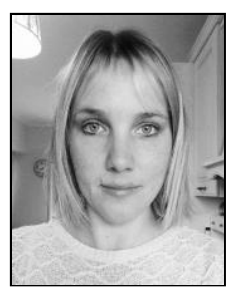

Sarah Vlachou has completed her undergraduate studies in early childhood education at the University of Western Macedonia (2008) and completed her training program in education of students with intellectual disabilities and learning difficulties at the Aristotle University of Thessaloniki (2015). She has also completed her Master's degree in Digital Applications and Innovation in the Department of informatics, Ionian University, Corfu (2021).

She has 10 years of experience teaching 4-6 year olds in public kindergartens in Greece. Currently she provides individual educational assistance in kindergartens in Corfu.

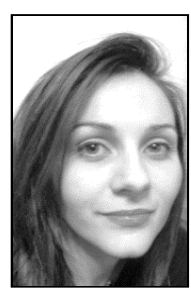

Eleni Malliou graduated from department of Theology of the University of Athens in 2009 and completed her master's degree in the Department of Informatics, Ionian University, Corfu (2021).

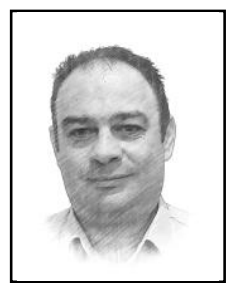

Spyridon Doukakis earned his $\mathrm{PhD}$ in Education \& Digital Technologies from the University of the Aegean and he completed his postdoctoral research at Ionian University in the field of Neuroeducation. He is a researcher and adjunct assistant professor at Ionian University. He has worked as a Special Counselor for Teacher Training at the Institute of Educational Policy for the Hellenic Ministry of Education. He has coauthored more than 90 papers in international journals and conferences as well as book chapters. He has received a Fulbright scholarship and has been awarded with the Harvard Prize Book Teacher Award. 